\section{Leaders need to realize that science can offer a route out of poverty}

Sir-Recently, Nature has given a lot of attention to science and technology in Latin America ${ }^{1-4}$. A key issue, however, needs to be addressed: in Latin America neither the public nor the private sectors, nor governments, acknowledge that science and technology development is an essential prerequisite for the cultural and economical advancement of society.

Scientific research is viewed as a marginal activity in Latin America. The construction of a strong local system of science and technology is not considered an important route towards development and cultural literacy in countries where most people lack basic health services, education and social security. It is not considered important for people's welfare amid poverty, underemployment, social marginalization, corruption and violence.

This attitude translates into fragile educational systems at all levels: poor academic standards among teachers, overcrowded classrooms, nonexistent or inadequate audiovisual equipment, violence at school, and a shortage of computers, laboratories and libraries.

Our countries allocate meagre budgets for scientific research and technology $\mathrm{R} \& \mathrm{D}$, both in absolute value and in terms of the gross national product (GNP). This results in very low publication rates in local academic outlets (if any exist) and international peer-reviewed journals. This in turn, reduces the number of people participating in these activities and leads to frustration among enthusiastic young students, who lack any motivation to dedicate their lives to such endeavours. This causes an excessive brain-drain to developed countries, reinforcing the downward spiral: lack of opportunities to reverse underdevelopment, increasing poverty, and the ever-widening gap from developed countries in all aspects.

Historically, Colombia's investment in science and technology has been one of the lowest in Latin America, amounting to much less than $0.25 \%$ of the GNP. In 1993-94 a thorough study was conducted to diagnose and make recommendations concerning the state of education, science and technology in Colombia ${ }^{5}$. The study was carried out by a team that included, among others, such eminent members as biochemist Manuel Patarroyo, neuroscientist Rodolfo Llinás and microbiologist Angela Restrepo, and the Nobel prizewinning writer Gabriel García Márquez. Among the recommendations was an increase in science and technology education and research expenditure to $2 \%$ of the GNP by 2000 .

Last year, the entire budget of Colombia's Institute for Science and Technology (Colciencias) amounted to less than US $\$ 15$ million, around $0.17 \%$ of the GNP. The severity of this crisis was dramatically illustrated last month, when a first-world-based private bank repossessed all the scientific equipment of Patarroyo's Instituto de Inmunología, "on the basis of outstanding debts" ${ }^{6}$. During recent years, this situation in Colombia has been exacerbated by a deep economic recession coupled with a bloody civil war.

In addition to the grossly insufficient development of science and technology in Latin America (which, I believe, is true of the developing world in general), the international scientific community imposes its own burdens. Journal subscriptions, memberships to scientific societies, page charges for accepted papers, registrations at scientific meetings, are all assigned with the research budgets of wealthier countries in mind. Hence they contribute to preventing scientists in lowincome countries from participating in the worldwide scientific community.

Germán Poveda

Graduate Programme in Water Resources, Universidad Nacional de Colombia, Medellín, AA 1027, Colombia

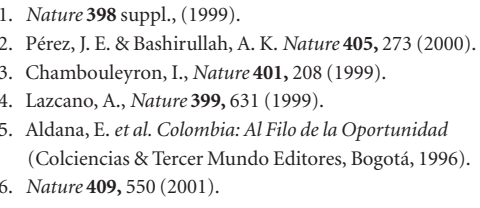

\section{Secret behind Hungary's stellar intellects}

Sir - Vaclav Smil's charming essay (Nature 409,$21 ; 2000$ ) revealed the genius loci of turn-of-the-century Budapest. As he says, some of the greatest figures in twentiethcentury science came from one small quarter of the city: Leo Szilard, Dennis Gabor, Eugene Wigner, John von Neumann and Edward Teller were born there (along with the writer Arthur Koestler) between 1898 and 1908, shortly after Theodore von Kármán and George de Hevesy. Andrew Grove and John Kemeny were later born in the same area.

But Smil omitted mention of Szilard's brilliant explanation of how this had come about. When Enrico Fermi, wondering at the immensity of the Universe and the certainty of life on planets orbiting stars in our Galaxy, asked why no beings from outer space had arrived, Szilard responded: "They are among us, but they call themselves Hungarians." How could one be sure? "Because they speak a language no one else can understand!"

I refer readers to The Leo Szilard Centenary Volume, edited by George Marx and published by the Eotvos Physical Society in 1998 (Fo Utca 68, Budapest H-1027, Hungary), for scientific documentation.

Leon Eisenberg

Department of Social Medicine, Harvard Medical School, 641 Huntington Avenue, Boston, Massachusetts 02115-6019, USA

\section{Why didn't flood of print launch science in China?}

Sir - Adrian Johns wrote in his Words essay ${ }^{1}$ that "science originated partly from a need to master as many [words] as possible", and that the impetus for this need came from "the development of printing in the mid-fifteenth century".

Printing was, of course, first developed in Tang Dynasty China (AD 618-907). The earliest surviving example of printed text is a 'dharani sutra' scroll printed between 704 and 751, now kept in Pulguksa Temple, Kyongju, Korea, and the earliest extant example of a printed book is the Diamond Sutra of 868, now kept in the British Museum. Both were printed in China.

It is therefore doubtful that the sudden deluge of printed material in fifteenthcentury Europe was a major cause of the Scientific Revolution. It has been estimated that, by 1700 or even 1800 , more written and printed pages existed in Chinese than in all other languages of the world put together ${ }^{2,3}$. Creel also estimates that, until the middle of the eighteenth century, more books had been published in Chinese than in all other languages put together".

The most prolific printing period in history was probably not the European Renaissance, but the Qing Dynasty (1644-1911). It was noted that "of the quarter of a million titles of Chinese publications known to have accumulated throughout the dynasties, no less than one half were produced during this period, the greatest amount in all history" ${ }^{25}$.

If the ready availability of printed material were indeed the main impetus for the Scientific Revolution, it would have happened in China, and not in Europe.

\section{P.-L. Chau}

Department of Biochemistry, University of

Cambridge, Cambridge CB2 1QW, UK

. Nature 409, 287 (2001)

2. Swingle, W. T. Bulletin of the American Library Association 11, 121 (1917).

3. Latourette, K. S. The Chinese: Their History and Culture 770 (Macmillan, New York, 1946).

4. Creel, H. G. Chinese Writing 15 (American Council on Education, Washington DC, 1943)

5. Needham, J. \& Tsien, T.-H. Science and Civilisation in China vol. 5, pt 1, 190 (Cambridge Univ. Press, Cambridge, 1985). 